\title{
Article \\ Improvement of the Iraqi Super Grid Performance Using HVDC/HVAC Links by the Integration of Large-Scale Renewable Energy Sources
}

\author{
Israa Ismael Hussein *(D), Sirine Essallah *(D) and Adel Khedher
}

Citation: Hussein, I.I.; Essallah, S.; Khedher, A. Improvement of the Iraqi Super Grid Performance Using HVDC/HVAC Links by the Integration of Large-Scale Renewable Energy Sources. Energies 2022, 15, 1142. https://doi.org/10.3390/ en15031142

Academic Editor: Javier Contreras

Received: 29 December 2021

Accepted: 1 February 2022

Published: 3 February 2022

Publisher's Note: MDPI stays neutral with regard to jurisdictional claims in published maps and institutional affiliations.

Copyright: (C) 2022 by the authors. Licensee MDPI, Basel, Switzerland. This article is an open access article distributed under the terms and conditions of the Creative Commons Attribution (CC BY) license (https:// creativecommons.org/licenses/by/ $4.0 /)$.
LATIS-Laboratory of Advanced Technology and Intelligent Systems, Ecole Nationale d'Ingénieurs de Sousse, Université de Sousse, Sousse 4023, Tunisia; adel.khedher@eniso.u-sousse.tn

* Correspondence: eng.israaismaeel@gmail.com (I.I.H.); sirinesallah@gmail.com (S.E.)

\begin{abstract}
The increasing use of renewable energy sources (RES) and their integration into transmission systems requires extensive studies to get more benefits from these sources. Stability analysis is one of the most crucial issues in these systems, and therefore needs to be studied in depth. In this paper, an analytical study was conducted for the stability assessment of the Iraqi super grid after adding a solar power plant with a capacity of $1000 \mathrm{MW}$ using both HVAC and HVDC links for comparison purposes. Thus, the objective of this study was to determine the best way to integrate RES into the power grid while improving its performance. The system's stability was evaluated for two types of faults: line and bus disturbances. The strength of the grid and its ability to absorb the newly added energy was also studied. The simulations were performed with the PSS/E software using the Newton-Raphson method for a $500 \mathrm{~km}$ transmission line length. The results showed that the HVDC link outperforms the HVAC link in improving the overall performance of the power system.
\end{abstract}

Keywords: stability analysis; power flow; HVAC; HVDC; transmission line; RES; SCR

\section{Introduction}

Currently, the electric power system faces new challenges, such as combating air pollution and reducing dependence on fossil fuels. Renewable energy sources (RES), although unconventional, can provide promising solutions to these challenges, but the integration of RES into the regular power system planning and operation is still limited [1,2].

Renewable energy sources are critical components of contemporary systems and one of the answers for meeting rising demand. Renewable energy is included in the generating mix, making it a suitable solution to the issue of electricity scarcity [3]. The ever-increasing need for electrical energy has been satisfied mainly through burning fossil fuels and converting their heat to electrical power. Excessive exploitation of natural resources has raised worries about greenhouse gas emissions, pollution, and harmful environmental consequences. Additionally, it emphasizes the sustainability of the generation necessary to fulfil the world's energy demand in the following decades using non-renewable fossil fuels. Renewable energy sources such as the sun, wind, and tides answer these problems [4].

Recent expansion in the electric power market and increased integration of RES into the power system have created new network design and management problems. As a result, it is necessary to conduct thorough research and analysis of the influence of integrated renewable energy sources on the current power system [5-7].

As electricity demand increases, the power system has extended [8]. As a result, the continuous load increase and the power system expansion may affect voltage stability and make the reactive power unstable [9-11]. The HVAC power transmission line is one major components of the electric power system, whose primary function is to transport electric power from the production centre to a load centre (usually separated by long distances) with minimal losses [12-14]. 
The high voltage level of power transmission has reduced losses and made transmission more cost-effective. However, due to some limitations of AC transmission, such as the lack of power flow control in AC lines and the inability to connect two asynchronous AC systems, the need for further study and investigation of DC transmission was reestablished. Even after discovering mercury-arc valves, which allowed conversion of AC to DC, the ratings remained insufficient to re-establish DC transmission in bulk power systems [15].

The development of a new generation of mercury arc valves with more complex properties by Uno Lamm enabled the reintroduction of DC transmission in 1950 [16,17]. Afterwards, significant advances in HVDC technology have occurred in recent decades. Many studies have been performed to investigate it in detail further to better understand its components and benefits over traditional AC systems [18,19]. HVDC transmission enables RES to transfer many thousand kilometres with low losses. This method permits the integration of enormous amounts of solar energy into the existing power system [16]. This integration affects several aspects of HVAC, including power flow, losses, stability, and short-circuit levels. As a result, it is critical to examine the consequences, as noted earlier, when adding new production stations and lines to the traditional network $[20,21]$.

In [20], Md. Mizanur Rahman et al. compared HVAC and HVDC power transmission systems. The study was accomplished for both topologies through the multi types of faults. The findings reveal that the 'fault current' in the HVAC transmission system is much higher than in the HVDC transmission system for every given fault scenario. The consequences of 'fault current' are particularly damaging in HVAC transmission systems, but they are soft, insignificant, and less dangerous in HVDC transmission systems.

Other researchers have investigated the integration of solar energy with the grid. In [22], the researcher explored the reasons, advantages, and challenges of integrating RES into the power system. Authors in [21] reviewed solar technologies. They concluded that their increased efficiency, low cost, and low pollution have resulted in their application in various energy projects, including building-integrated systems, pumps, solar home systems, desalination plants, and photovoltaic and thermal (PVT) collector technology.

In [23], a single-layer control system for coordinating the operation of battery energy storage system (BESS) and wind power plants via multi-terminal high voltage direct current (HVDC) were presented and demonstrated. The findings of this study have shown the suitability of the proposed coordinated controller to provide flexibility and decrease requirements for balancing power.

The study in [24] proposed the installation of a diode rectifier HVDC (DR-HVDC) for the new offshore wind farm (OWF) in the Jeju Island power system. The outcomes of this study revealed that the power system in steady and transient states is more stable, and the application of the DR-HVDC reduces costs and increases the reliability of an OWF compared to a conventional HVDC.

The aforementioned overviews mainly focused on the comparison of HVAC and HVDC system performances in the presence of renewable energy sources in normal and fault conditions. Consequently, this paper investigates the RES integration possibilities in the Iraqi super grid and examines its impact on HVAC and HVDC systems. The main objective is to assess the power system stability in normal and fault conditions in the presence of RES and to evaluate its performance and strength for HVAC and HVDC links.

This paper is structured as follows: Section 2 presents a power flow and short circuit level analysis of the HVDC and HVAC systems in the presence of large-scale renewable energy sources. HVDC modelling and control are described in Section 3. Section 4 details the stability analysis of the HVDC/HVAC power system integrated with large-scale solar plant energy. The results and the discussion are summarized in Section 5. Finally, the main conclusions are stated in the last section. 


\section{Power Flow and Short Circuit Level Analysis}

\subsection{Power Flow Problem Formulation}

Power system planning studies are crucial for designing power system components such as generators, transmission lines, and transformers, protecting them from damage, and assuring their operation and stability. When this aim is achieved, power loss should be reduced to a minimum while considering other restrictions [25]. Thus, power flow analysis (PF) is crucial for planning future expansions, determining system stability, and determining the most cost-effective operation of existing systems. The PF problem models the nonlinear relationships between the supplied power at the system buses, the power loads, the bus voltages, and the circuit parameters. The basic information of the PF solution is the voltage magnitude, the phase angle at each bus, and the real and reactive power flow in each transmission line. Additional information such as current flow and power losses can be computed from these values. These values are determined by the solution of nodal power balance equations. Because these equations are nonlinear, iterative procedures such as Newton-Raphson, Gauss-Seidel, and fast-decoupled methods are often used to solve this problem [26]. However, most industry-based research currently uses the NewtonRaphson iterative approach (NR), which is more dependable in terms of convergence, computationally quicker (usually, two iterations are enough), and requires less storage [27]. The transmission line can be modelled as shown in Figure 1.

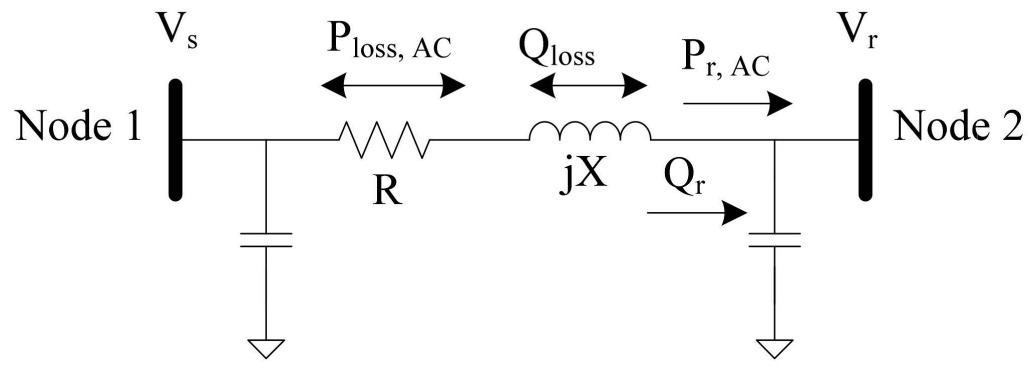

Figure 1. Transmission line model.

According to Kirchhoff's law, the relationship between the injected current I into the network nodes and the bus voltage $V$ is described by the admittance matrix $Y$ as follows $[28,29]$ :

$$
\left[\begin{array}{c}
I_{1} \\
I_{2} \\
\vdots \\
I_{N}
\end{array}\right]=\left[\begin{array}{cccc}
Y_{11} & Y_{12} & \cdots & Y_{1 N} \\
Y_{21} & Y_{22} & \cdots & Y_{2 N} \\
\vdots & \vdots & \vdots & \vdots \\
Y_{N 1} & Y_{N 2} & \cdots & Y_{N N}
\end{array}\right]\left[\begin{array}{c}
V_{1} \\
V_{2} \\
\vdots \\
V_{N}
\end{array}\right]
$$

where $Y_{i j}$ is the line's admittance between the $i$ th and $j$ th buses, $V_{i}$ is the voltage on the ith bus, and $I_{i}$ is the current on the $i$ th bus.

The injected current at node $i$ can be expressed as follows:

$$
I_{i}=\sum_{k=1}^{N} Y_{i k} V_{k}
$$

The active and reactive powers injected at node $i$ are rewritten as follows [29]:

$$
\left\{\begin{aligned}
P_{i} & =\sum_{i=1}^{N}\left|Y_{i k}\right|\left|V_{i}\right|\left|V_{k}\right| \cos \left(\delta_{i}-\delta_{k}-\theta_{i k}\right) \\
Q_{i} & =\sum_{i=1}^{N}\left|Y_{i k}\right|\left|V_{i}\right|\left|V_{k}\right| \sin \left(\delta_{i}-\delta_{k}-\theta_{i k}\right)
\end{aligned}\right.
$$

where $\delta_{i}$ and $\theta_{i k}$ are, respectively, the voltage and the admittance matrix phase angles. 
The power flow problem consists of solving a system of non-linear equations to determine the voltage magnitude and phase angle at each bus $i$ of the network. Thus, the power problem is formulated as follows:

$$
\left\{\begin{array}{c}
\Delta P_{i}=P_{g i}-P_{c i}-\sum_{i=1}^{N}\left|Y_{i k}\right|\left|V_{i}\right|\left|V_{k}\right| \cos \left(\delta_{i}-\delta_{k}-\theta_{i k}\right)=0 \\
\Delta Q_{i}=Q_{g i}-Q_{c i}-\sum_{i=1}^{N}\left|Y_{i k}\right|\left|V_{i}\right|\left|V_{k}\right| \sin \left(\delta_{i}-\delta_{k}-\theta_{i k}\right)=0
\end{array}\right.
$$

where $P_{g i}$ and $Q_{g i}$ are the generated active and reactive powers, respectively, and $P_{c i}$ and $Q_{c i}$ are the active and reactive loads, respectively.

The voltage magnitude and phase angle of each bus are computed as follows:

$$
\left\{\begin{array}{c}
\left|V_{k}\right|^{(r+1)}=\left|V_{k}\right|^{r}+\left|\Delta V_{k}\right|^{r} \\
\delta_{k}^{(r+1)}=\delta_{k}^{r}+\Delta \delta_{k}^{r}
\end{array}\right.
$$

where $r$ is the number of iterations.

\subsection{Short-Circuit Analysis}

Short-circuit level (SCL) is an electrical fault that occurs when a large current flows down an alternate channel, resulting in severe equipment damage, power failure, physical injury, or death [10]. Short circuit analysis determines the system's ability to create a short circuit current, the electrodynamic resistance capability of the wire and equipment, and the magnitude of the short circuit current relative to the interrupting power of overcurrent protection devices. The effects of a short-circuit often depend on the type, duration, and location (near sparking or arcing locations) of the fault. Phase-to-ground faults account for $80 \%$ of faults; three-phase faults account for less than $5 \%$ of initial faults, and $15 \%$ are phase-to-phase faults [30].

- $\quad$ Phase-to-ground fault

This form of failure activates the zero-sequence impedance, $Z_{0}$. Unless spinning equipment is involved, short-circuit current, $I_{S C O}$ is less than three-phase fault current (lower zero-sequence impedance). Calculations for $I_{S C O}$ may be necessary depending on the neutral system (earthing system configuration), assuming the established thresholds for zero-sequence (high voltage) or earth-fault (low voltage) safety devices [31].

- Three-phase fault

This fault manifests itself in all three phases; short-circuit current can be expressed as:

$$
I_{S C}=\frac{U / \sqrt{3}}{Z_{S C}}
$$

where $U$ refers to the phase-to-phase voltage that corresponds to the transformer's no-load voltage. It is approximately $3 \%$ to $5 \%$ higher than the on-load voltage across the terminals. Computing the short-circuit current involves the calculation of $Z_{S C}$, which is equal to the sum of all impedances through which $I_{S C}$ flows from the generator to the point of failure. The impedances of the power sources and the lines are defined as the impedance per phase that is "Positive-sequence":

$$
Z_{S C}=\sqrt{\left(\sum R\right)^{2}+\left(\sum X\right)^{2}}
$$

where $\sum R$ and $\sum X$ are the total resistance and reactance of a sequence, respectively.

\section{HVDC System: Modelling and Control}

The prospects of a future HVDC grid are anticipated to meet the rising power demand and incorporate renewable energy sources into the grid [32-35]. An HVDC grid can provide 
the extra required power capacity, and its economy for long-distance transmission is ideal for integrating remote renewable sources into the grid.

Popular HVDC converter topologies are the line commutated converter (LCC), the voltage source converter (VSC), and the newly developed modular multilevel converter (VSC-MMC) [36-39]. Historically, LCCs have been employed as rectifiers and inverters in an HVDC system. MMCs, however, offer many advantages over LCCs, including a smaller footprint, low harmonic output, control of both real and reactive power, black start capability, and no chance of commutation failure [32,35,36,40]. These characteristics make MMCs excellent for use as inverters in urban load centres where compactness, fault recovery, and power quality are critical [34,35]. However, LCCs offer a higher current capacity and are more economical and technologically mature compared to MMCs [41]. The drawbacks of an LCC are typically not a concern at the rectifier due to the general availability of land at a remote location and proximity to generation [34,35]. The hybrid LCC-MMC system can be a practical solution for riding through DC side faults and multiterminal connections, which are foreseen in the future HVDC grid. This paper pays attention to the LCC-HVDC topology applied to the Iraqi super grid.

\subsection{LCC-HVDC System}

In Figure 2, a typical LCC-HVDC link between two AC systems is illustrated. It consists of two terminals linked by a direct current connection. Each terminal has converters, transformers, filters, reactive power equipment, a control station, and other components. This figure shows two direct current lines with an electrode in each converter station to supply the ground return path [42].

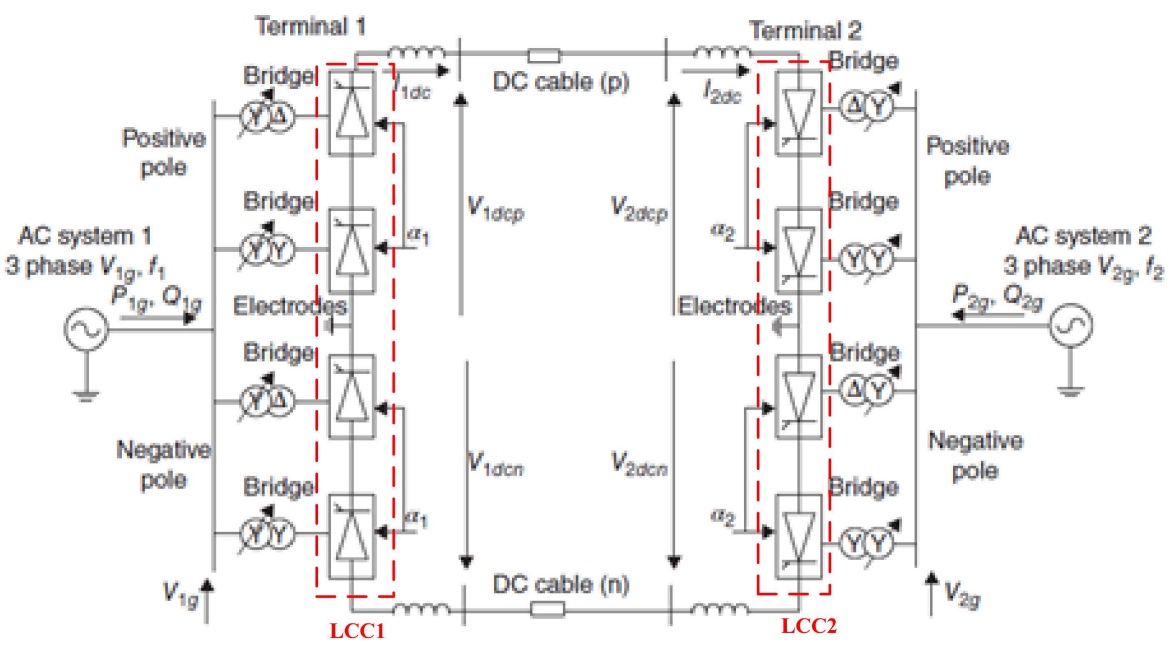

Figure 2. A typical high-voltage direct current system (12-pulse bipolar with ground return).

An LCC converter's fundamental structure is a three-phase full-wave bridge referred to as a "Graetz Bridge" or a six-pulse bridge. In practice, two of these Graetz bridges are connected in series to make a 12-pulse bridge, eliminating the need for harmonic filtering and producing twice the DC voltage. Harmonic reduction of DC and AC voltages is accomplished by introducing a 30-degree phase shift between the AC voltages provided at the upper and lower 6-pulse bridges. The 30-degree phase shift is achieved by connecting a Y-connected transformer to the top 6-pulse bridge's secondary and a delta-connected transformer to the lower 6-pulse bridge's secondary. The switching from one thyristor switch to another on the same DC pole is referred to as commutation. The converter is called 'line commutated' because it depends on the line voltage for commutation to occur. Due to the use of unidirectional thyristor valves, the LCC cannot operate with reverse currents [35]. 
The DC terminal voltage, $V_{d c}$, is the difference between the positive and negative pole voltages, $V_{d c p}$ and $V_{d c n}$, respectively. For rectifier operation, $V_{d c}$ may be mathematically described as follows:

$$
V_{d c}=V_{d c 0} \cos \alpha-I_{d c} B R_{c}
$$

with

$$
V_{d c 0}=\frac{3 \sqrt{2} B T V_{L L}}{\pi}
$$

In Equation (8), $V_{d c 0}$ is the voltage at zero ignition angle $\alpha, R_{c}$ is the commutation resistance, $B$ denotes the number of six-pulse bridges, $I_{d c}$ is the DC line current, $V_{L L}$ is the line-to-line voltage of the $\mathrm{AC}$ grid, and $T$ is the transformer ratio. The ignition angle is used to postpone valve commutation. The commutation resistance $R_{c}=\frac{3}{\pi} \times X_{c}$ is equal to the voltage drop across the source side line inductance, $L_{c}$.

For inverter operation, a comparable equation is defined as:

$$
V_{d c}=-V_{d c 0} \cos \gamma+I_{d c} B R_{c}
$$

where $\gamma$ is the extinction angle.

\subsection{HVDC System Control with LCC Converters}

The control's purpose is to regulate the flow of electricity over the HVDC circuit. Adjusting the DC internal voltages $V_{d c 0} \cos \alpha$ for the rectifier and $-V_{d c 0} \cos \gamma$, the inverter allows for the adjustment of the voltage and current. The rectifier's ignition angle $\alpha$, and the inverter extinction angle $\gamma$, can be quickly adjusted through controls to respond within 1 to $10 \mathrm{~ms}$ [35]. The tap changers may also be adjusted after the initial quick response from the ignition angle to ensure that $\alpha$ is brought back within a desirable range. The tap change response ranges from $5 \mathrm{~s}$ to $6 \mathrm{~s}$ per step [35]. Key factors to be satisfied by the controls are [35]: prevention of large fluctuations in DC, $I_{d c}$ under AC disturbances; operation with high power factors; operation near rated voltages; and prevention of commutation failure, which is a major concern in LCC inverters. The DC voltage is a function of the power factor: $V_{d c} \approx-V_{d c 0} \cos \varnothing$, where $\cos \varnothing$ is the power factor. Operation with a high power factor is desirable: to increase rated power; minimize valve stress; reduce losses and current ratings of $\mathrm{AC}$ system equipment connected to the converter; reduce the reduction in $\mathrm{AC}$ voltage due to higher loading, and minimize reactive power supply costs [35]. A high power factor is achieved with low ignition/extinction angles, $\alpha$ for the rectifier and $\gamma$ for the inverter. Typically, $\alpha$ is maintained within $10^{\circ} \leq \alpha \leq 20^{\circ}$ to ensure a high power factor without limiting the control range [42]. Conventional HVDC characteristic control curves are depicted in Figure 3. The rectifier and inverter controls are visually shown in these curves under normal and AC fault conditions. The characteristic curves for the rectifier and inverter are taken concerning the DC terminal of the rectifier, i.e., the rectifier DC terminal voltage on the y-axis and the x-axis, $V_{d c}$ and current, $I_{d c}$, respectively. The inverter voltage with respect to the rectifier DC terminal considers the voltage drop across the HVDC line: $V_{d c}=V_{d i n v}+R_{\text {line }} I_{d c}$. Consequently, the operating point of the system is the intersection of the rectifier and inverter characteristic curves. As seen in Figure 3, the rectifier runs under constant current control, whereas the inverter functions under constant extinction angle control (i.e., constant $\gamma$ control). The abbreviations CIA, CEA, CC, CM, and VDCOL represent the constant ignition angle, constant extinction angle, constant current, current margin, and voltage-dependent current order limit, respectively. 


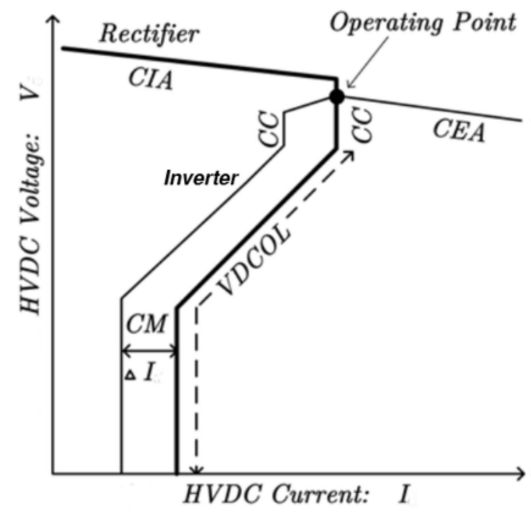

Figure 3. Characteristic control curve for HVDC line with LCC converters.

\subsection{Fault Handling Strategy}

This section summarizes an LCC's technique for dealing with AC and DC problems.

\subsubsection{AC Faults}

The $\mathrm{DC}$ voltage is a function of the AC line-to-line voltage; hence, a decrease in the $\mathrm{AC}$ voltage caused by a fault results in a drop in the DC voltage. Figure 4 depicts the HVDC LCC characteristic curves under AC fault conditions [43].

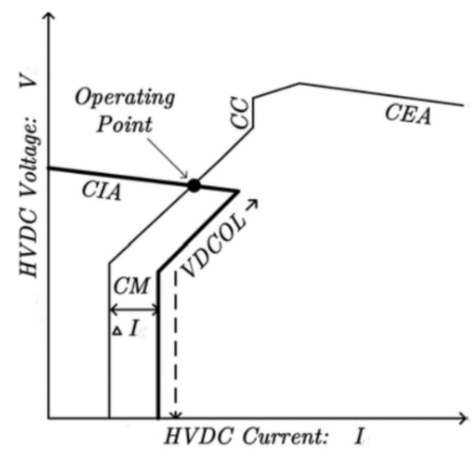

(a)

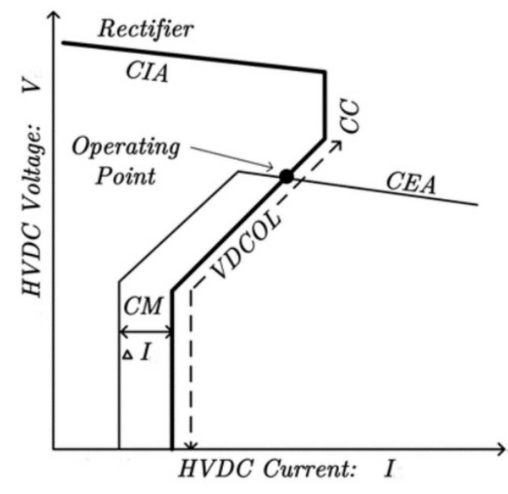

(b)

Figure 4. HVDC LCC characteristic curves under AC fault conditions: (a) rectifier AC fault, (b) inverter AC fault.

As shown in this figure, the current is regulated by a voltage-dependent current order limit (VDCOL), which is used to limit the reactive power demand from the AC system during the fault and hence minimizes the danger of commutation failure. The current margin $(\mathrm{CM})$, which is commonly set from $0.1 \mathrm{pu}$ to $0.15 \mathrm{pu}$, is established to guarantee that the two characteristic curves overlap at a single point during decreased voltage operation. If the AC voltage remains low, tap changers will be changed to bring the system voltages and currents up to parity with the ignition angle, $\alpha$, back to their normal operating range. Figure $4 \mathrm{a}, \mathrm{b}$ shows the operating point during rectifier and inverter side faults. For rectifier side faults close to the converter station, there is a significant voltage drop, which would require the inverter station to operate with a large extinction angle, $\gamma$, resulting in large reactive power demand. As a result, the DC system is shut down under extremely low voltages. A voltage drop from $10 \%$ up to $15 \%$ may cause commutation failure [35,42]. If the voltage drop is significant, the converter valves are blocked until the fault is cleared and the voltage recovers to its normal value. 


\subsubsection{Pole-to-Ground Fault}

At a DC pole-to-ground fault, the converter switches from a constant angle extinction command to constant current control. The converter operates at a reduced current order for the rectifier of the $\mathrm{CM}$ quantity. The reduced current restricts the reactive power demand of the AC system. The rectifier switches its operating mode from constant current control to constant ignition angle control, $\alpha$. During the DC fault condition, a fault current equal to the $\mathrm{CM}$ is sustained. Otherwise, fast-acting line protection can be employed during a poleto-ground DC fault. The rectifier and inverter both operate to invert their DC terminal voltage. The fault current is seeking to exit the fault trail and enter the converters. However, due to the unidirectional diodes, the current rapidly decreases to zero.

\section{Stability Analysis of the HVDC/HVAC Power System in the Presence of Large-Scale Solar Plant}

\subsection{System Strength Evaluation}

\subsubsection{Short Circuit Ratio (SCR)}

When it comes to incorporating renewable energy sources, system stability is a prevalent issue. The system strength, which indicates the system variables' sensitivity to different disturbances, affects the performance of various components in a power system. Short circuit ratio (SCR) is a metric that indicates the strength of a network bus compared to the rated power of a device. Frequently, the SCR is used to indicate the system's strength. When disturbances are introduced, a more robust system generates few fluctuations in voltage and other variables. The equipment's $S C R$ is defined as its short circuit capacity ratio to its MW rating on the bus $[44,45]$. A robust system has an SCR of more than 3, whereas a poor or severely weak system has an SCR between 3 and 2 or less. The short circuit ratio is a critical parameter in power electronic applications such as the power converters that connect renewable energy sources (wind and solar energy) to conventional power grids. When used with insufficient AC systems, HVDC/FACTs devices based on current source converters exhibit problems. When HVDC/FACTs devices are coupled to weak AC systems, particular technologies are frequently needed (short circuit ratio of less than 3).

When the SCR is close to one, capacitor-commutated or voltage-source-based converters are used for HVDC applications. If such technologies are not accessible, specialized studies will be necessary to assess the impact and provide solutions for avoiding or mitigating harmful consequences. Low levels of SCR may result in difficulties such as high overvoltages, low-frequency resonances, and control system instability [46,47].

SCR is often described as the ratio of the short circuit capacity of the bus on which the device is placed to the MW rating of the device. According to this definition, SCR is expressed as follows:

$$
S C R=\frac{S_{i}}{P_{d c}}
$$

where $S_{i}$ denotes the short circuit capacity of the bus before the device's connection, and $P_{d c}$ denotes the device's MW rating.

Table 1 summarizes the system strength assessment categorization.

Table 1. Short circuit ratio and AC system strength.

\begin{tabular}{cc}
\hline Classification & Short Circuit Ratio (SCR) \\
\hline Strong system & SCR $>3$ \\
Weak system & $2<$ SCR $\leq 3$ \\
Very weak system & SCR $<2$ \\
\hline
\end{tabular}




\subsubsection{Weighted Short Circuit Ratio $\left(W_{S C R}\right)$}

The weighted short circuit ratio $\left(W_{S C R}\right)$ is a more suitable indicator, as it considers the influence of system interactions and provides a more accurate estimate of system strength. $W_{S C R}$ is given by:

$$
\begin{gathered}
W_{S C R}=\frac{\frac{\text { weighted } S_{i}}{N}}{\sum_{i}^{N} P_{d c i}} \\
W_{S C R}=\frac{\sum_{i}^{N} S_{i} \times P_{d c i} / \sum_{i}^{N} P_{d c i}}{\sum_{i}^{N} P_{d c i}} \\
W_{S C R}=\frac{\sum_{i}^{N} S_{i} \times P_{d c i}}{\left(\sum_{i}^{N} P_{d c i}\right)^{2}}
\end{gathered}
$$

where $S_{i}$ denotes the short circuit capacity of bus $i$ before connecting solar plant $i, P_{d c i}$ denotes the MW rating of the solar plant $i$ to be connected, $N$ is the number of solar plants that are completely interconnected, and $i$ denotes the solar plant index [45].

\subsection{Stability Analysis}

The term "power system stability" refers to studying the dynamics of the power system in the presence of failures. After being exposed to a disturbance, the stability of a power system refers to its capacity to resume regular or steady operation. When a specific disturbance occurs in the system, power system instability may be defined as the loss of synchronism (i.e., specific synchronous machines moving out of phase). Three distinct kinds of stability are affected: steady-state, transient, and dynamic stability [27,29].

System frequency and voltage levels are two critical parameters in alternating current power systems. Furthermore, most electric power produced in power systems is a threephase alternating current where generators operate synchronously. During the normal operation of a power system, the mechanical and electromagnetic torques acting on each generator must balance, and all synchronous generators must revolve at the same electrical speed in phase with the system frequency [48].

If the power system is subjected to severe disturbances such as short-circuit defects in transmission lines, it is possible to preserve generator synchronism. Transient stability is described in $[48,49]$ as the system's capacity to sustain generator synchronization in the presence of substantial failures. Otherwise, a lack of transient stability might continually induce rotor-angle variations and self-exciting power oscillations, further damaging power system components such as generators and transmission lines or even resulting in power system blackout [48].

As a result, the physical nature and methodology for transient stability should be thoroughly investigated to ensure power system security, particularly when new technologies such as high voltage direct current (HVDC) and renewable energy are integrated into power systems and have their own dynamic characteristics for transient stability. Consequently, the dynamic implications of such new technologies on the transient stability of power systems should be thoroughly researched for the intent of power system security [48].

Within this context, this paper assesses the power system's stability and evaluates its strengths versus disturbances after integrating large-scale renewable energy. Small signal rotor angle stability, which refers to the power system's ability to retain its synchronism under disturbances, is the considered one. The instability appears in rotor oscillations with increased amplitude owing to the lack of damping torque and an aperiodic mode stemming from the lack of synchronizing torque. The study is conducted on the Iraqi super grid, where the dynamic system behaviour is investigated before and after integrating the solar power plant using HVDC and HVAC links. The impact of line and bus outages on the system stability is examined for different cases using the PSS/E software. The latter utilizes statistics channels called spread angle, largest angle, smallest angle, and average angle. The smallest angle can be defined as the trace for smaller rotor angles recorded when applying 
disturbance. The largest rotor angle represents the trace of a larger angle recorded through disturbance. In contrast, the average rotor angle is the average value of the rotor angle recorded when applying disturbance. Finally, the spread rotor angle is the deviation of the angle when applying disturbance with respect to the steady-state rotor angle. If any generator goes out of step in the simulation, the angle spread will increase. Angle spread is, therefore, a good indicator of rotor angle instability.

The reference of stability limits, and all issues noted above, is the steady state analysis of the system in load flow equilibrium, which means that the smallest deviation in spread angle, largest angle, smallest angle, and average angle led to a good stability response.

\section{Results and Discussion}

\subsection{Iraqi Power System}

The electrical power system of Iraq is divided into three operational subsystems: from the control point of view, the North, Middle, and South regions, in addition to the Kurdistan region network, which is separate from the Iraqi network. The HVAC Iraqi transmission system operates with a frequency of $50 \mathrm{~Hz}$ and a transmission voltage of $132 \mathrm{kV}$ up to $400 \mathrm{kV}$. The power system under study is the Iraqi power grid (400 kV), which contains 41 buses, 25 of which are generating buses, and 72 transmission lines, as illustrated in Figure 5. The peak generation is $17,513 \mathrm{MW}$, and the peak loading is $24,679 \mathrm{MW}$, so the shortage is $7166 \mathrm{MW}$ based on the Iraqi centre load on 5 July 2020 [50].

Considering the information provided by the Iraqi Ministry of Electricity database, this work suggests adding a new transmission line with $1000 \mathrm{MW}$ supplied from a new solar plant (SP) connected to the secondary station named West Baghdad (BGW4). It has been assumed that this new solar plant, named SHMS, has a capacity of $1000 \mathrm{MW}$ and is used to feed the loads on bus BGW4 through a $500 \mathrm{~km}$ transmission line. To evaluate the strength of the Iraqi super grid and its stability versus disturbances after the integration of large-scale renewable energy, the dynamic system behaviour was assessed before and after integrating a solar power plant using bipolar HVDC and double line circuit HVAC links using the PSSE simulation tool. The test system parameters used in this study are summarized in Table 2.

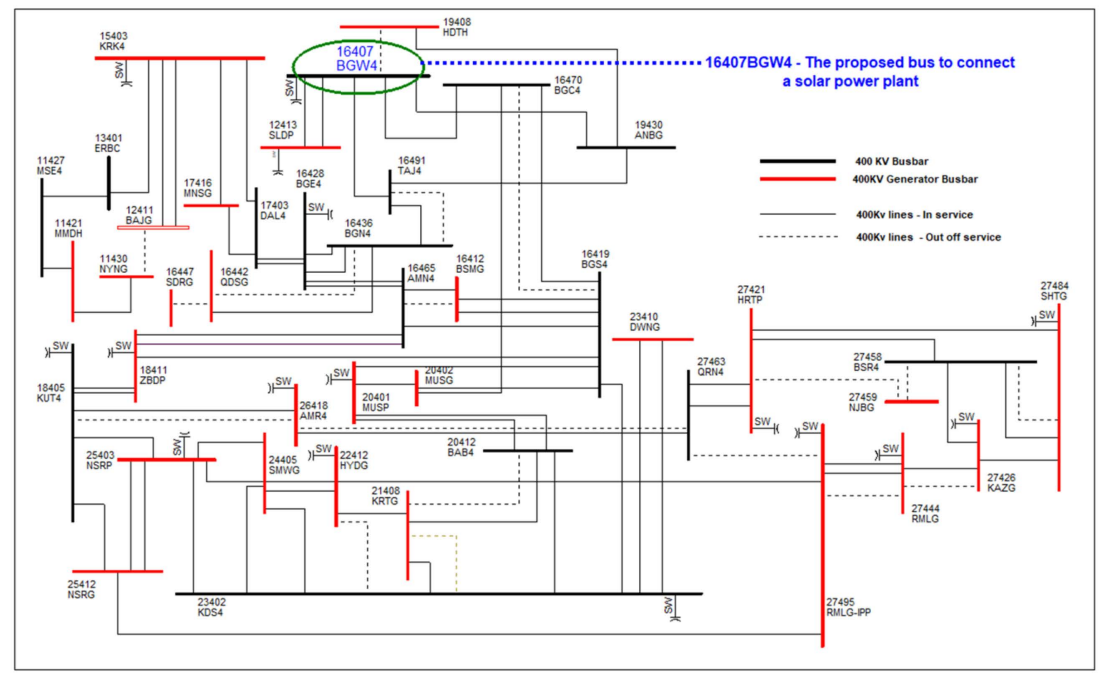

(a)

Figure 5. Cont. 


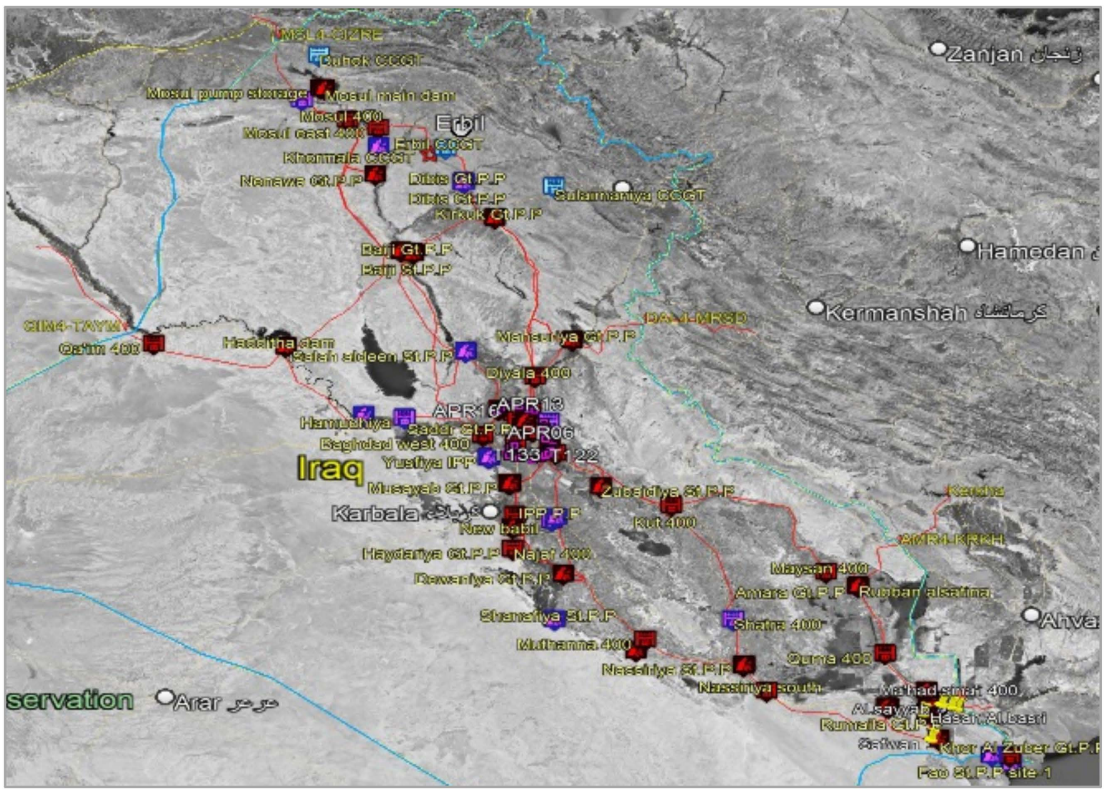

(b)

Figure 5. The Iraqi super grid: (a) single line diagram; (b) geographical overview.

Table 2. Model specification of case study.

\begin{tabular}{cc}
\hline Parameter & Value \\
\hline System frequency & $50 \mathrm{~Hz}$ \\
Rated AC voltage & $400 \mathrm{kV}$ \\
Rated power & $1000 \mathrm{MW}$ \\
Transformer ratio & $400 / 132 \mathrm{kV}$ \\
Line length & $500 \mathrm{~km}$ \\
\hline
\end{tabular}

\subsection{Power Flow and Short Circuit Levels Simulation Results}

Our previous work [51] included the study of the impact of the renewable energy penetration on the power load flow and short circuit levels using double circuit lines for HVAC and bipolar HVDC links. Simulation results demonstrated that the HVDC system surpasses the HVAC in power losses and SCL minimization. Additionally, results have shown that, for the HVAC link case, the short-circuit levels increase after adding a solar power plant and decrease progressively as the distance between this generation station and the load centre increases. Moreover, it was noted that the double circuit line provides acceptable power loss and SCL results. When HVDC links are used, the results showed that SCL considerably decreased whether the distance between the power plant and the load centre increase or decreases. Furthermore, it was noted that the power losses and the SCLs for bipolar links are significantly less than those provided by HVAC links.

\subsection{System Strengths Evaluation for Large-Scale Solar Plant Integration}

Numerical simulations were carried out using PSS/E software for the base system configuration (without any newly added power), the short-circuit levels for three-phase faults at the BGW4 bus, and its connections and are presented in Table 3. 
Table 3. Three phase short-circuit levels.

\begin{tabular}{ccc}
\hline Bus No. & Bus Name & $\begin{array}{c}\text { Three-Phase Short Circuit } \\
\text { Currents (A) }\end{array}$ \\
\hline 16407 & BGW4 & $29,501.2$ \\
12413 & SLDP & $19,715.9$ \\
16470 & BGC4 & $27,845.8$ \\
16491 & TAJ4 & $34,262.8$ \\
19430 & ANBG & $16,776.2$ \\
\hline
\end{tabular}

Subsequently, a new large-scale solar power plant with various capacities was added to the base system at BGW4 (bus no. 16407) using an HVDC link. The short circuit ratio is evaluated as indicated in Table 4.

Table 4. Solar power plant sizes and SCR value (assuming no interaction).

\begin{tabular}{ccc}
\hline $\begin{array}{c}\text { Solar Power Plant } \\
\text { Capacity (MW) }\end{array}$ & $\begin{array}{c}\text { Short Circuit } \\
\text { Capacity (MVA) }\end{array}$ & SCR \\
\hline 500 & & 23.6 \\
1000 & & 11.8 \\
1500 & 7.87 \\
2000 & 5.9 \\
3000 & & 3.93 \\
3500 & $11,800.48$ & 3.37 \\
3700 & & 3.19 \\
3800 & 3.11 \\
3900 & 3.03 \\
4000 & & 2.95 \\
5000 & & 2.36 \\
6000 & & 1.97 \\
\hline
\end{tabular}

The above results show that the system is strong until adding $3900 \mathrm{MW}$ and operates without problems after the integration of a solar power plant using an HVDC link; beyond this value, the system will be weak. Therefore, it can be concluded that the integration of solar power plant is bounded by the system strengths, which are further affected and exhibit weak and very weak conditions when the solar power generation capacity reaches 4000 MW.

With the integration of a $3900 \mathrm{MW}$ solar power capacity into the system at various points, the short circuit ratio is as shown in Table 5.

Table 5. Added solar power capacity and SCR evaluation.

\begin{tabular}{ccccc}
\hline Bus No. & Bus Name & $\begin{array}{c}\text { Short Circuit } \\
\text { Capacity (MVA) }\end{array}$ & $\begin{array}{c}\text { Solar Plant } \\
\text { Capacity (MW) }\end{array}$ & SCR \\
\hline 16407 & BGW4 & $11,800.48$ & 1500 & 7.87 \\
12413 & SLDP & 7886.36 & 500 & 15.77 \\
16470 & BGC4 & $11,138.32$ & 700 & 15.91 \\
16491 & TAJ4 & $13,704.8$ & 400 & 34.26 \\
19430 & ANBG & 6710.48 & 800 & 8.39 \\
\hline
\end{tabular}

Considering full interaction, by Equation (11) the actual weight of the short circuit ratio is: $W_{S C R}=2.65$.

The corresponding point of interconnection (POI) $W_{S C R}$ is just 2.65, although all SCRs at each point of interconnection exceed 3 , which would be an acceptable characteristic of connection to a strong system. This implies that when these solar plants are combined, the system strengths are significantly reduced compared to when each solar plant oscillates individually. 


\subsection{Dynamic Simulation Results and Discussion}

A two-terminal HVDC line was simulated using the CDC4T-DC line control model, as shown in Figure 6.

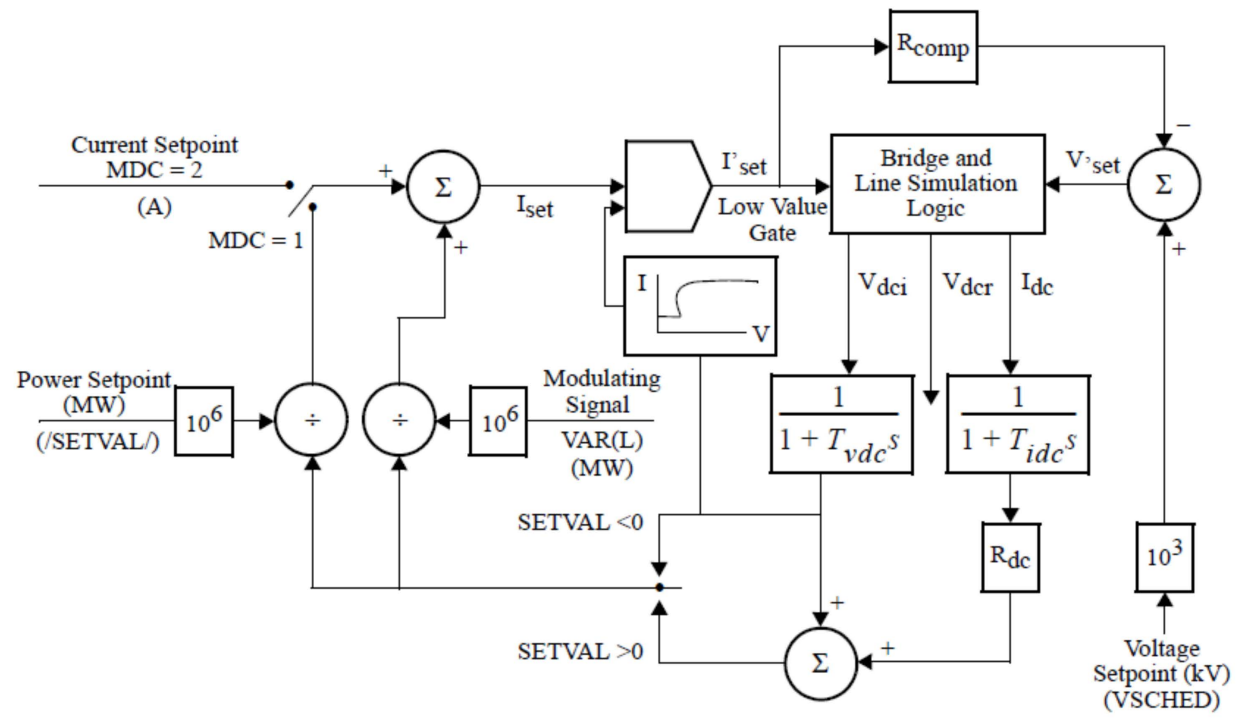

Figure 6. CDC4T-DC transmission line control model.

The CDC4T model assumes that an instantaneous response of the DC system to disturbances is coming from adjacent grids. It uses the same algebra as the power flow model to update converter parameters $(\alpha, \gamma)$ at every integration step. It assumes that converters can maintain the steady-state control algorithm using the same setpoints as in power flow. There is a special algorithm for simulating blocking and by-passing HVDC that uses some threshold voltages on AC and DC sides. Setting up these thresholds requires experience because they are very sensitive to how strong the interconnection to the system is.

The parameters of HVDC system control are shown in Table 6.

Table 6. Parameters of the HVDC system model.

\begin{tabular}{ccc}
\hline System Parameters & Rectifier & Inverter \\
\hline AC voltage base $(\mathrm{kV})$ & 400 & 400 \\
Tap setting $(\mathrm{pu})$ & 1.10 & 1.10 \\
Nominal DC voltage $(\mathrm{kV})$ & \pm 400 & \pm 400 \\
Nominal DC current $(\mathrm{kA})$ & 1.250 & 1.250 \\
Transformer impedance $(\mathrm{pu})$ & 0.14 & 0.14 \\
System frequency $(\mathrm{Hz})$ & 50 & 50 \\
Minimum angle $(\mathrm{deg})$ & $\alpha=15.863^{\circ}$ & $\alpha=18^{\circ}$ \\
Power $(\mathrm{MW})$ & 1000 & 1000 \\
\hline
\end{tabular}

In this study, the impact of line and bus outages on the system stability has been simulated for three cases:

1. First case: the base system;

2. Second case: after the integration of the solar plant using an overhead AC doublecircuit line;

3. Third case: after integrating the solar plant using a bipolar DC link for each pole. 


\section{- Line disturbance}

First, stability analysis of the system was carried out by applying a line fault at the point node named 19436HMD4-19437ANBP loaded 300MW; the fault is applied after the simulation initiation (at $1 \mathrm{~s}$ ) and is cleared after $0.06 \mathrm{~s}$.

Figure 7 shows the system response during the onset of the short circuit: the spread angle, the largest angle, the smallest angle, and the average angle of the system, respectively.

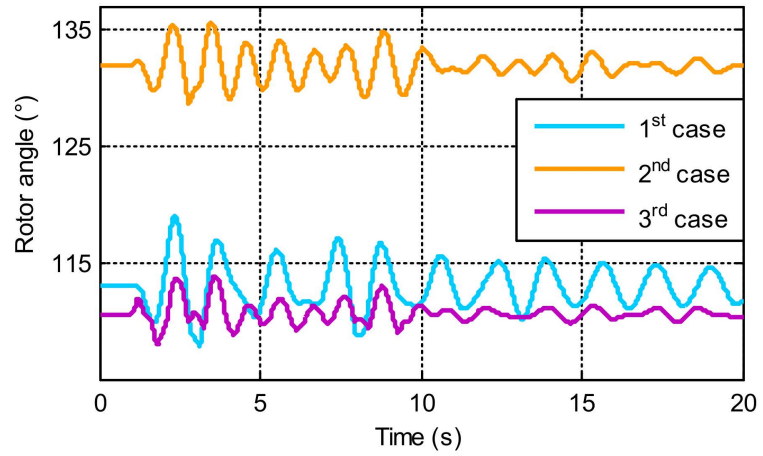

(a)

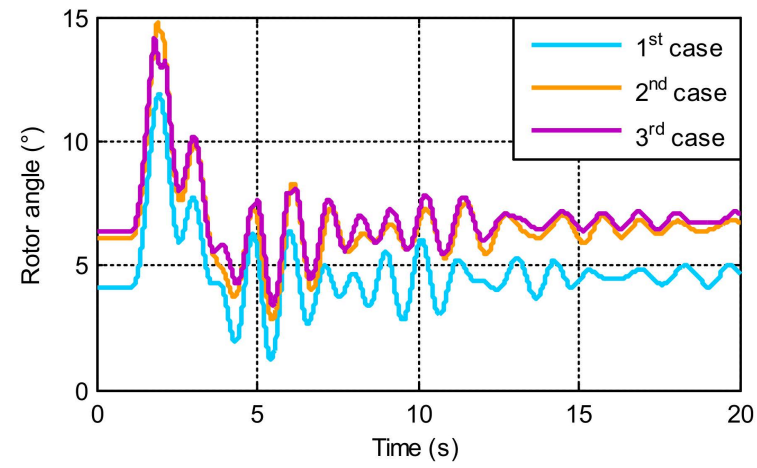

(c)

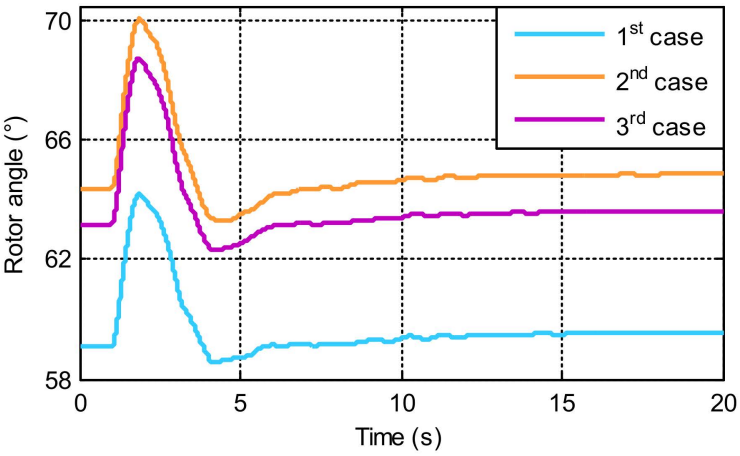

(b)

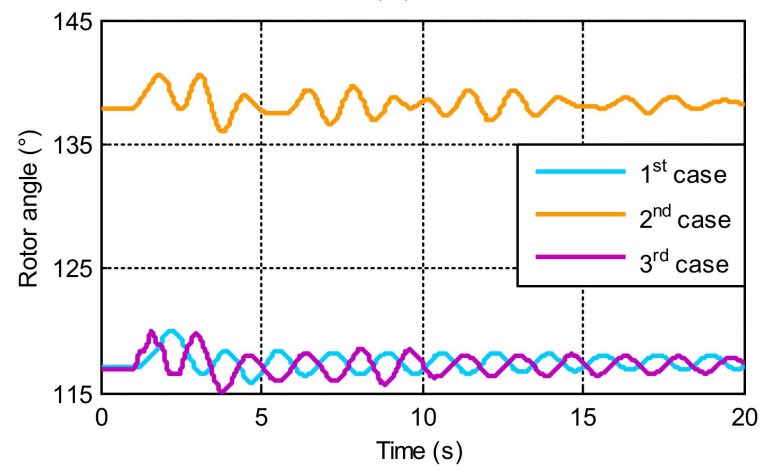

(d)

Figure 7. Transient response of the Iraqi super grid against a line disturbance for different cases: (a) spread angle; (b) average angle; (c) smallest angle; (d) largest angle.

It can be noted in Figure 7a that the overall spread angle of the system had much better results for case 3 than for the other cases. HVDC proved its ability to improve the total spread angle of the system and make it smaller than its value even before adding a solar power plant. As for Figure $7 \mathrm{~b}$, which represents the average angle of the system, it can be noted that there is a clear difference that case 3 achieved better results than case 2 . Figure $7 \mathrm{c}$ represents the smallest angle in the system, where the HVDC also kept the angle value from falling compared to the other cases. Although Figure $7 \mathrm{~d}$ represents the largest angle of the system, it was proved that case 3 behaves close to the system before adding a solar power plant, thus keeping the value of the largest angle almost unchanged.

The voltage response during the short circuit occurrence at different points in the power system was also studied for all test cases. Figure 8 illustrates the results of the test points at buses no. 16840-GQD11 and 16227-YSP13. These plots prove that the voltage at bus no. $16840-G Q D 11$ is estimated to be $1.010 \mathrm{pu}, 1.035 \mathrm{pu}$, and $1.020 \mathrm{pu}$ for cases 1, 2, and 3 respectively (Figure $8 \mathrm{a}$ ); these values falls to $0.8 \mathrm{pu}$ during the fault. The voltage at bus no. 16227-YSP13 is estimated to be 1.02 pu for cases 1 and 3 (Figure $8 \mathrm{~b}$ ) during the pre-fault. This value falls to $1.01 \mathrm{pu}$ during the fault. After that, the voltage shows some oscillations but always lies within the stability limits. However, for case 2, the voltage gap is slightly larger compared to other cases. The fail is not far from the other cases, and it is caused by the decreased system inertia due to HVDC characteristics (HVDC does not have inertia). 


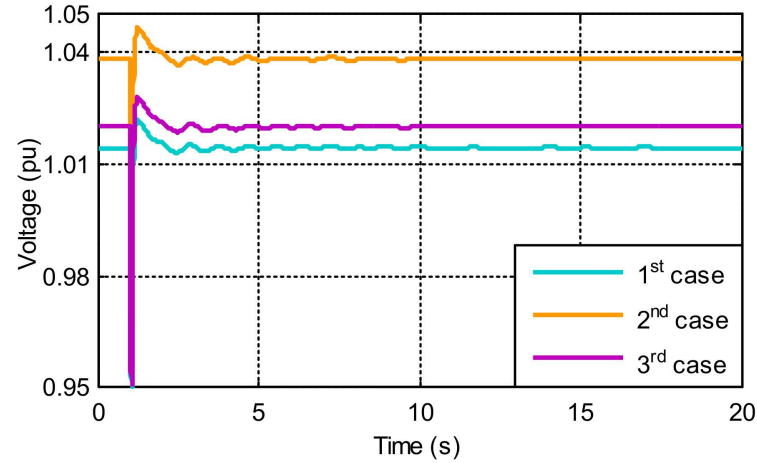

(a)

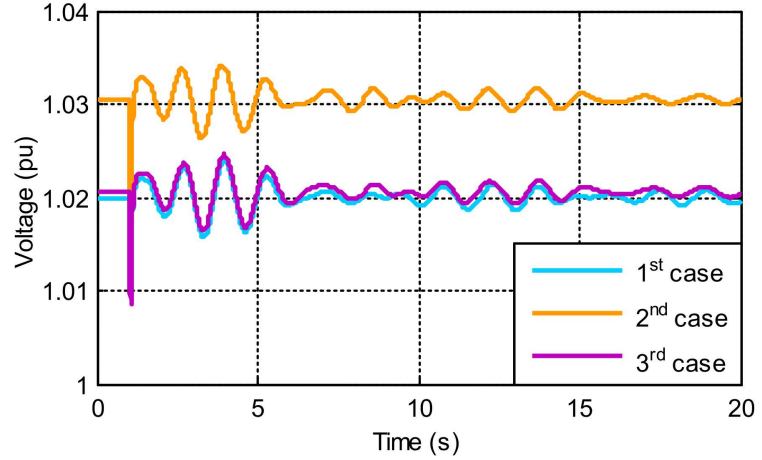

(b)

Figure 8. Voltage transient response of the power system versus line disturbance at different points: (a) voltage at bus no. 16840-GQD11; (b) voltage at bus no. 16227-YSP13.

- Bus disturbance

For this fault scenario, the power system stability has been evaluated for a bus disturbance at buses 18806-ZBP6, 16225-YSP11, and 16226-YSP12 loaded 558, 286, $286 \mathrm{MW,}$ respectively. The same fault conditions, time occurrence, and duration are maintained.

Figure 9 illustrates the transient response of all systems during the short circuit occurrence, angle spread, largest angle, smallest angle, and average angle of the system, respectively.

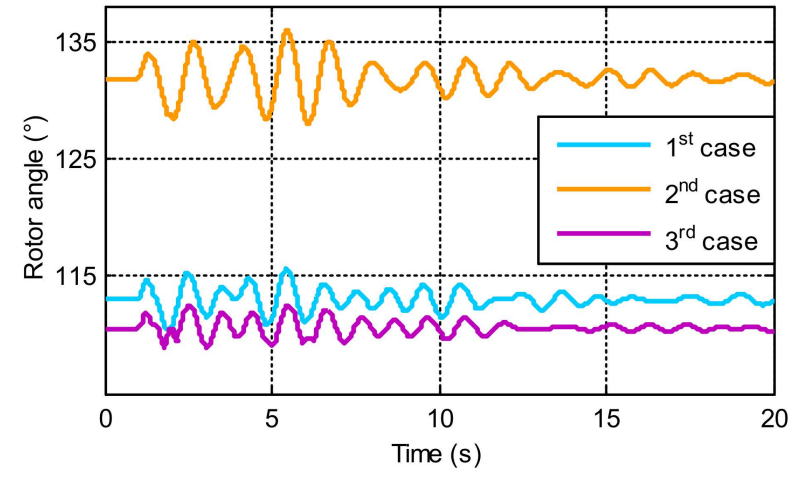

(a)

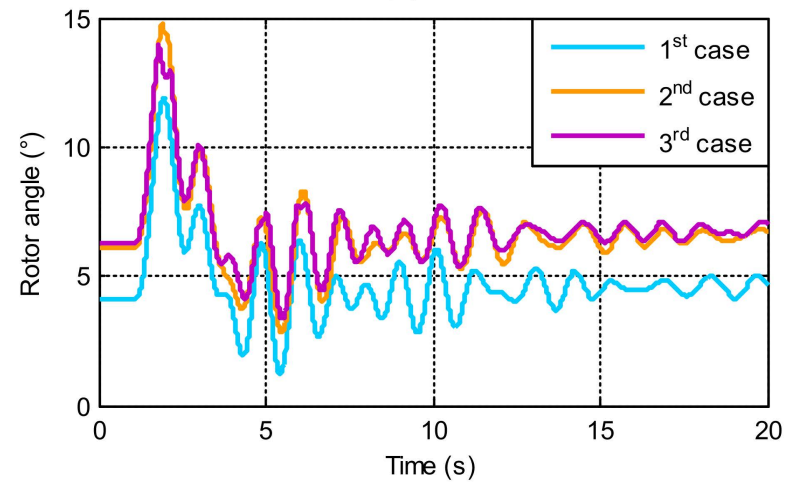

(c)

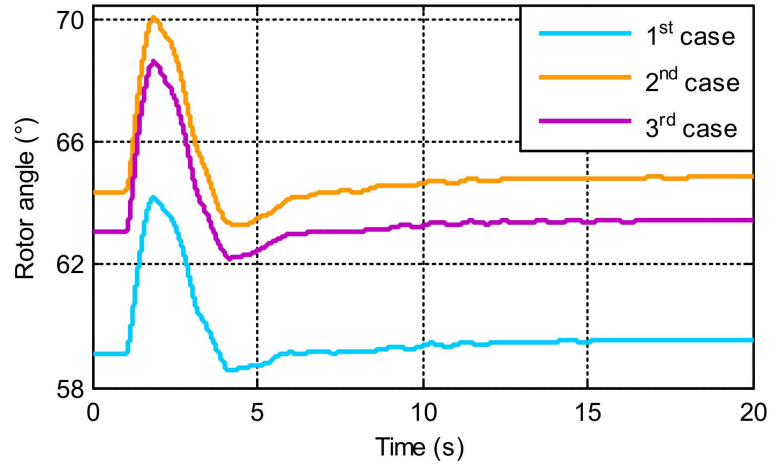

(b)

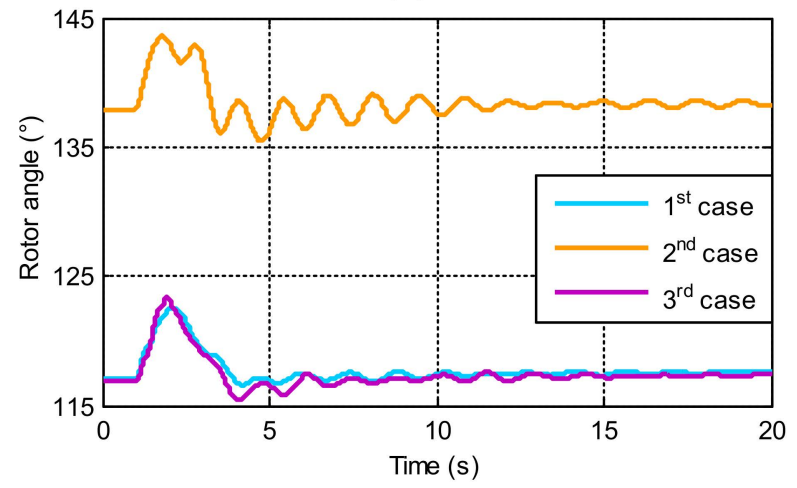

(d)

Figure 9. Transient response of the Iraqi super grid against a bus disturbance for studied test cases: (a) spread angle; (b) average angle; (c) smallest angle; (d) largest angle.

The simulation results show a similar response to the first fault scenario with a slight improvement in the HVDC that shows better oscillations damping of the generator angles. Figure 10 illustrates the transient voltage response during the bus disturbance scenario at 
system points no. 16840-GQD11, and no. 16227-YSP13. Figure 10b shows that the voltage drop for this fault scenario has reached $0.18 \mathrm{pu}$. However, the power system has regained its stability after removing the fault.

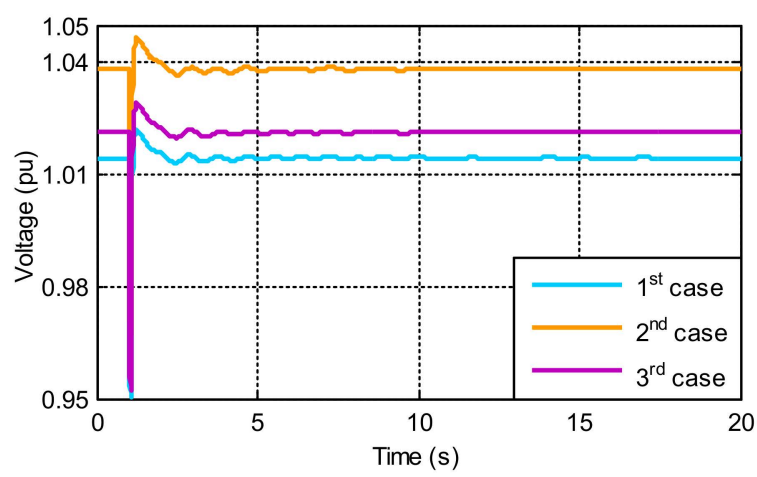

(a)

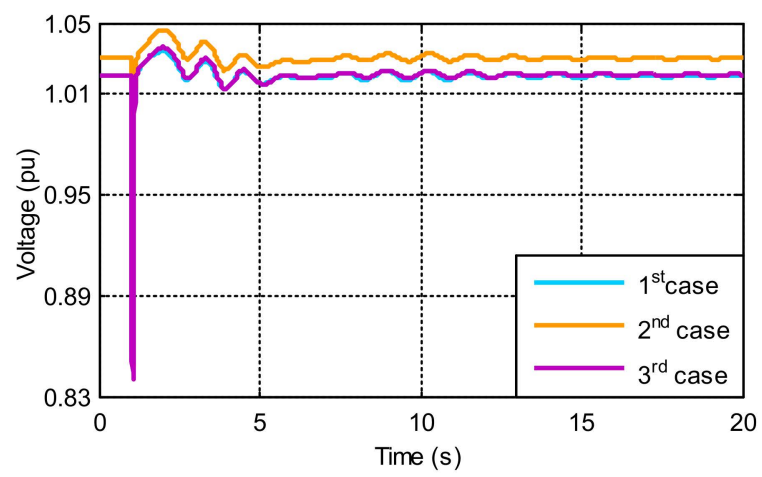

(b)

Figure 10. Voltage transient response of the power system versus bus disturbance at different points: (a) voltage at bus no. 16840-GQD11; (b) voltage at bus no. 16227-YSP13.

\section{- $\quad$ Line and bus disturbance}

In this scenario, both line and bus disturbances have been applied. The Iraqi super grid stability has been examined for a line outage at 19436HMD4-19437ANBP and bus disconnection at buses no. 18806-ZBP6, no. 16225-YSP11, and no. 16226-YSP12. For this fault scenario, a total generation of $1730 \mathrm{MW}$ is disconnected. Figures 11 and 12 illustrate the transient response of the power system angles and voltages to this fault scenario.

The simulation results described in the figures above show that when the line and bus faults are applied simultaneously, the angle deviation of the power system is greater than for the case where each fault is applied separately. Nevertheless, the Iraqi super grid has proven its resilience to such a severe fault. Moreover, as for previous fault scenarios, the HVDC system has outperformed the HVAC system, showing a better resilience to faults, resulting in a small deviation of the angle and better damping of the oscillations. Furthermore, the transient voltage response depicted in Figure 12 shows a similar result as for the bus disturbance case, which demonstrates that this type of fault affects the system voltage more than the line outage. However, after the fault clears, the system voltage shows some oscillations but lies within the stability limits.

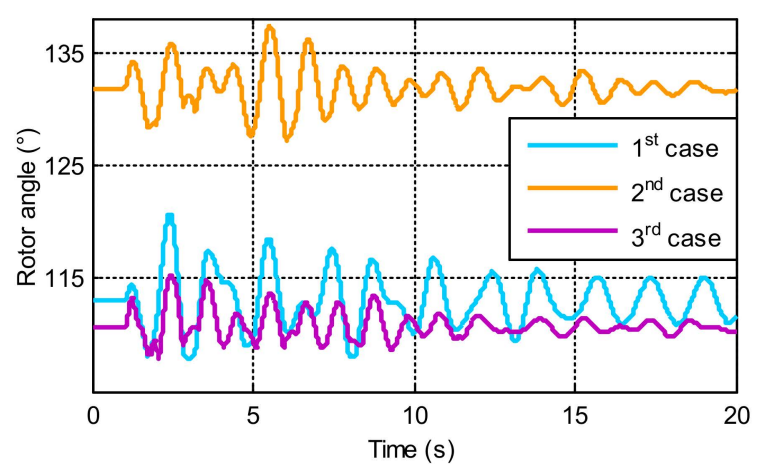

(a)

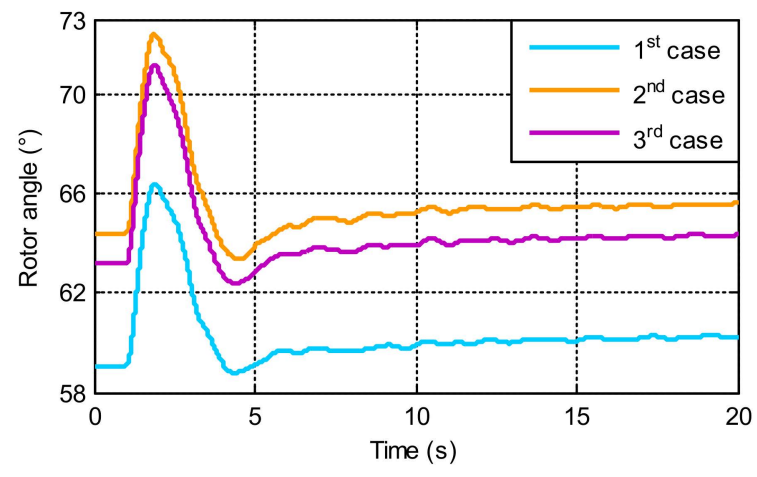

(b)

Figure 11. Cont. 


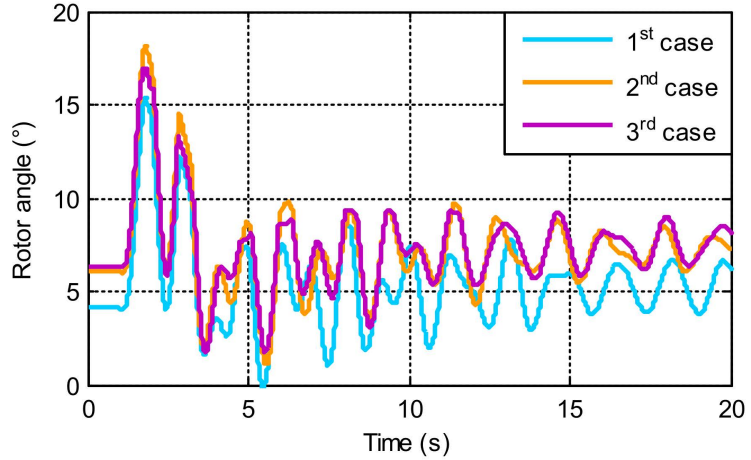

(c)

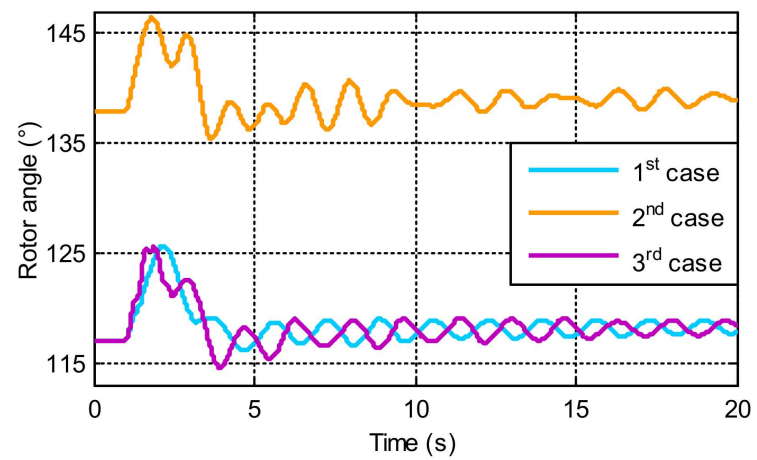

(d)

Figure 11. Transient response of the studied power system versus a simultaneous line and bus disturbance for studied test cases: (a) spread angle; (b) average angle; (c) smallest angle; (d) largest angle.

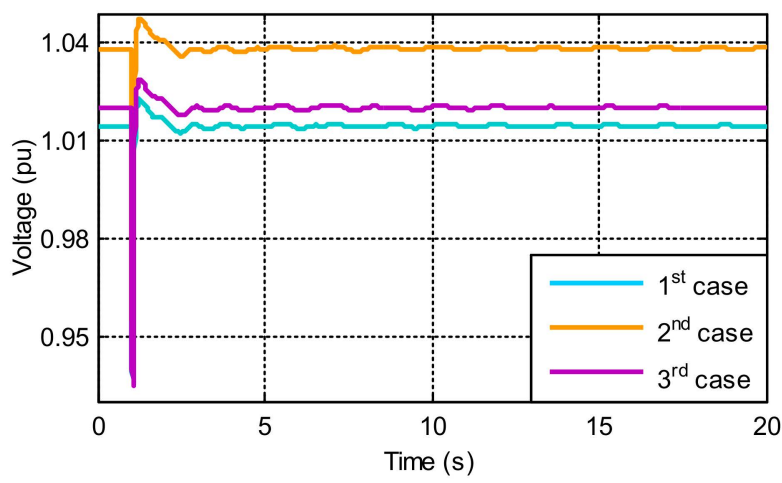

(a)

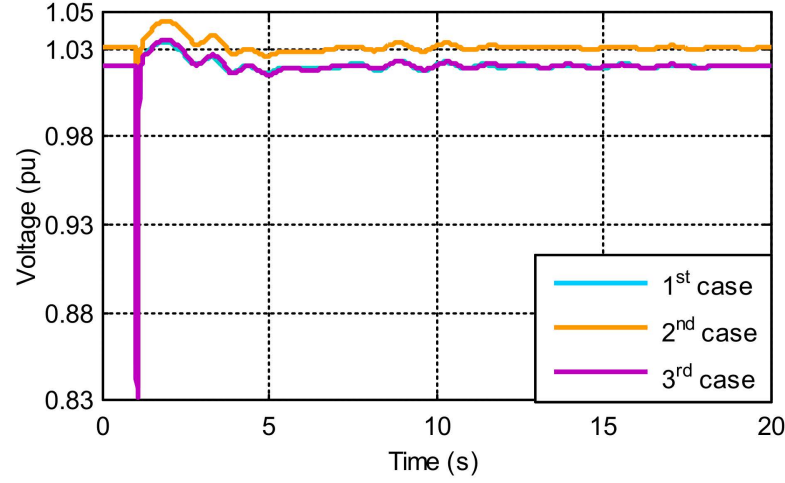

(b)

Figure 12. Voltage transient response of the power system versus a simultaneous line and bus disturbance at different points: (a) voltage at bus no. 16840-GQD11; (b) voltage at bus no. 16227-YSP13.

\section{Conclusions}

This paper discussed the impact of large-scale renewable energy integration with both HVAC and HVDC systems, considering stability analysis. Simulation results prove that despite the severity of the applied faults, the Iraqi super grid has demonstrated its resilience to such a fault. Additionally, the HVDC system has outperformed the HVAC system, showing a better resilience to faults, resulting in a small deviation of the angle and better damping of the oscillations. The dynamic system behaviour in the presence of HVDC lines has shown better performance and a more stable state for permanent faults than pure HVAC networks. Moreover, the HVDC lines have a better performance when comparing transient with permanent faults. It provides additional voltage support to congested transmission lines, leading to system stability and reliability improvement. However, the most significant benefit of adding an HVDC line in accidents is the system's ability to withstand a considerable loss of power without significantly impacting the network's stability, which was observed when studying the line and bus disturbance.

Author Contributions: Conceptualization, I.I.H. and S.E.; methodology, I.I.H. and S.E.; software, I.I.H.; validation, S.E. and A.K.; investigation, I.I.H.; writing-original draft preparation, I.I.H.; writing-review and editing, S.E.; visualization, I.I.H.; supervision, S.E. and A.K. All authors have read and agreed to the published version of the manuscript.

Funding: This research received no external funding.

Institutional Review Board Statement: Not applicable. 
Informed Consent Statement: Not applicable.

Data Availability Statement: Not applicable.

Conflicts of Interest: The authors declare no conflict of interest.

\section{References}

1. Pavan, K.N.R.; Meikandasivam, S. Power quality enhancement in a grid-connected hybrid system with coordinated PQ theory \& fractional order PID controller in DPFC. Sustain. Energy Grids Netw. 2020, 21, 100317.

2. International Renewable Energy Agency (IRENA). Renewable Capacity Statistics. Available online: https://www.irena.org/ publications / 2019/Mar/Renewable-Capacity-Statistics-2019 (accessed on 2 April 2019).

3. Sirine, E.; Adel, K.; Bouallegue, A. Integration of distributed generation in electrical grid: Optimal placement and sizing under different load conditions. Comput. Electr. Eng. 2019, 79, 106461.

4. Swain, P.; Jagadish, S.; Mahesh, K.U. Integration of renewable sources of energy into power grid. In Proceedings of the 2017 IEEE Region 10 Symposium (TENSYMP), Cochin, India, 14-16 July 2017.

5. Bayindir, R.; Demirbas, S.; Irmak, E.; Cetinkaya, U.; Ova, A.; Yesil, M. Effects of renewable energy sources on the power system. In Proceedings of the 2016 IEEE International power electronics and motion control conference (PEMC), Varna, Bulgaria, 25-28 September 2016

6. National Renewable Energy Laboratory (NREL). Using Distributed Energy Resources. Available online: http:/ /www.nrel.gov (accessed on 10 April 2019).

7. Ahsan, S. Smart grid integration of renewable energy systems. In Proceedings of the 2018 7th International Conference on Renewable Energy Research and Applications (ICRERA), Paris, France, 14-17 October 2018.

8. Ali, M.E.; Abou, H.A.; Amer, N.A.; Yahia, S. Mitigation voltage sag using DVR with power distribution networks for enhancing the power system quality. IJEEAS 2018, 1, 2600-7495.

9. Ali, M.E.; Amer, N.A. Multi-control module static VAR compensation techniques for enhancement of power system quality. Ann. Fac. Eng. Int. J. Eng. 2018. ISSN 2601-2332. Available online: http:/ / annals.fih.upt.ro/pdf-full/2018/ANNALS-2018-3-06.pdf (accessed on 10 April 2019).

10. Ali, M.E.; Yahia, S.; Abou, H.A.; Amer, N.A. HVDC over HVAC transmission system: Fault conditions stability study. Int. J. Res. Stud. Electr. Electron. Eng. (IJRSEEE) 2019, 5, $24-37$.

11. Masoud, R.; Mahmoud, S.M.; Mojtaba, S.; Soheil, R. Online estimation of power system separation as controlled islanding scheme in the presence of inter-area oscillations. Sustain. Energy Grids Netw. 2020, 21, 100306.

12. Ning, L. An evaluation of the HVAC load potential for providing load balancing service. IEEE Trans. Smart Grid 2012, 3, 1263-1270.

13. Assefa, A. Study on Conversion of Existing HVAC Lines to Hybrid HVAC/HVDC Transmission Line to Increase Transmission Capacity and Efficiency. Master's Thesis, Addis Ababa University, Addis Ababa, Ethiopia, December 2015.

14. Marten, A.K.; Akmatov, V.; Sørensen, T.B.; Stornowski, R.; Westermann, D.; Brosinsky, C. Kriegers flak-combined grid solution: Coordinated cross-border control of a meshed HVAC/HVDC offshore wind power grid. IET Renew. Power Gener. 2018, 12, 1493-1499.

15. Abdulrahman, A.; Santiago, B.; Omar; Grain, A.; Callum, M. HVDC transmission: Technology review, market trends and future outlook. Renew. Sustain. Energy Rev. 2019, 112, 530-554.

16. Zhou, L.; Ruopei, Z.; Yazhou, L.; Yan, H.; Jinming, H.; Xiaoling, Z.; Xiao, P.Z. Recent developments in HVDC transmission systems to support renewable energy integration. Glob. Energy Interconnect. 2018, 1, 595-607.

17. Andrea, T.; Tilman, W.; Spyros, C. Market integration of HVDC lines: Internalizing HVDC losses in market clearing. IEEE Trans. Power Syst. 2019, 35, 451-461.

18. Tarek, A.; Shahadat, H.L.; Mahammad, A.H.; Pin, J.K.; Safwan, A.R.; Chong, T.Y.; Sieh, K.T.; Kashem, M.M. Dynamic modeling of HVDC for power system stability assessment: A review, issues, and recommendations. Energies 2021, 14, 4829. [CrossRef]

19. Umar, J.; Neelam, M.; Muhammad, J.; Omar, A.; Ghulam, A.; Nasim, U.; Shahariar, C.; Kuaanan, T.; Khurram, S.; Umair, T. A systematic review of key challenges in hybrid HVAC-HVDC grids. Energies 2021, 14, 5451. [CrossRef]

20. Rahman, M.M.; Rabbi, M.F.; Islam, M.K.; Rahman, F.M.M. HVDC over HVAC power transmission system: Fault current analysis and effect comparison. In Proceedings of the International Conference on Electrical Engineering and Information \& Communication Technology (ICEEICT), Dhaka, Bangladesh, 10-12 April 2014.

21. Nwaigwe, K.N.; Mutabilwa, P.; Dintwa, E. An Overview of Solar power (PV systems) integration into electricity grids. Mater. Sci. Energy Technol. 2019, 2, 629-633. [CrossRef]

22. Zahedi, A. A review of drivers, benefits, and challenges in integrating renewable energy sources into electricity grid. Renew. Sustain. Energy Rev. 2011, 15, 4775-4779. [CrossRef]

23. Martha, N.A.; Francisco, G.L.; Juan, M.R.; Manuel, B. A coordinated control of offshore wind power and BESS to provide power system flexibility. Energies 2021, 14, 4650. [CrossRef]

24. Sang, H.C.; Min, H.K.; Seung, H.S.; Eel, H.K. Analysis of the jeju island power system with an offshore wind farm applied to a diode rectifier HVDC. Energies 2019, 12, 4515. [CrossRef]

25. Andersson, G. Power System Analysis; Lecture 227-0526-00; ITET ETH: Zürich, Schwitzerland, 2012. 
26. Umar, H.R.; Mahmoud, S.; Joakim, M.; Joakim, W.; Nicholas, E. Review of probabilistic load flow approaches for power distribution systems with photovoltaic generation and electric vehicle charging. Electr. Power Energy Syst. 2020, $120,106003$.

27. John, J.G.; William, D.S. Power System Analysis, International ed.; McGraw-Hill: Singapore, 1994; pp. $329-376$.

28. Archita, V.; Sweety, J.; Sneha, M.; Vinita, G.; Mahendra, L. Comparison between different load flow methodologies by analyzing various bus systems. Int. J. Electr. Eng. 2016, 9, 127-138.

29. Saadat, H. Power System Analysis; Mc Grawhill: New York, NY, USA, 1999; Volume 2.

30. Subhan, R. Load flow based electrical system design and short circuit analysis. Master's Thesis, Kadir Has University, Istanbul, Turkey, February 2019.

31. Benoît, d.M.N.; Frédéric, D.; Christophe, P. Calculation of Short-Circuit Currents, Cahier Technique no.; 158, Schneider Electric. 2005, p. 35. Available online: https://www.se.com/ww/en/download/document/ECT158/ (accessed on 10 July 2020).

32. Noman, A.; Arif, H.; Dirk, V.H.; Lidong, Z.; Hans, P.N. Prospects and challenges of future HVDC supergrids with modular multilevel converters. In Proceedings of the 14th European Conference on Power Electronics and Applications, European Conference, Birmingham, UK, 30 August-1 September 2011.

33. Noman, A.; Staffan, N.; Hans, P.N.; Arif, H.; Dirk, V.H.; Lidong, Z.; Lennart, H. HVDC supergrids with modular multilevel converters; the power transmission backbone of the future. In Proceedings of the International Multi-Conference on Systems, Signals and Devices, Chemnitz, Germany, 20-23 March 2012.

34. Spahic, E.; Schettler, F.; Varma, D.; Dorn, J. Impact of the DC technology on transmission grids. In Proceedings of the 11th IET International Conference on AC and DC Power Transmission, Birmingham, UK, 10-12 February 2015.

35. Udeesha, S.A. Hybrid LCC and multi-terminal full-bridge modular multilevel converters for HVDC transmission. Master's Thesis, University of Toronto, Toronto, ON, Canada, 2015.

36. Younggi, L.; Shenghui, C.; Sungmin, K.; Seung, K.S. Control of hybrid HVDC transmission system with LCC and FB-MMC. In Proceedings of the Energy Conversion Congress and Exposition (ECCE), Pittsburgh, PA, USA, 14-18 September 2014.

37. Mike, B.; Damian, S.V.R.; Roger, S. HVDC Circuit Breakers-A Review. IEEE Access 2020, 8, 211829-211848.

38. Yunkai, L.; Ting, L.; Quan, T.; Yunling, W.; Chuan, Y.; Xiaoxi, Y.; Yang, L. Comparison of UPFC, SVC and STATCOM in improving commutation failure immunity of LCC-HVDC systems. IEEE Access 2020, 8, 135298-135307.

39. Xiaodong, L.; Zheng, X. Feasibility evaluation on elimination of DC filters for line-commutated converter-based high-voltage direct current projects in new situations. Energies 2021, 14, 5770. [CrossRef]

40. Alireza, N.; Jiaqi, L.; Frans, D.; Georgios, D.D. Modular multilevel converters for HVDC Applications: Review on converter cells and functionalities. IEEE Trans. Power Electron. 2014, 30, 18-36.

41. Geng, T.; Zheng, X. A LCC and MMC Hybrid HVDC Topology with DC Line Fault Clearance Capability. Electr. Power Energy Syst. 2014, 62, 419-428.

42. Drgan, J.; Khaled, A. High-Voltage Direct-Current Transmission, 1st ed.; John Wiley \& Sons: Chichester, UK, 2015 ; pp. 5-118.

43. Zhao, J.; Tao, Y. Control Characteristic Analysis and Coordinated Strategy Design for Hybrid HVDC With Multi-Infeed MMC Inverters. Front. Energy Res. 2021, 558. [CrossRef]

44. Abbey, C.; Khodabakhchian, B.; Zhou, F.; Dennetière, S.; Mahseredjian, J.; Joos, G. Transient modeling and comparison of wind generator topologies. In Proceedings of the International Conference on Power Systems Transients, Montreal, QC, Canada, 19-23 June 2005.

45. Yang, Z.; Shun, H.F.H.; John, S.; José, C.; Jeffrey, B.; Ehsan, R. Evaluating system strength for large-scale wind plant integration. In Proceedings of the 2014 IEEE PES General Meeting, Conference \& Exposition, National Harbor, MD, USA, $27-31$ July 2014.

46. ABB. Comp. ERCOT CREZ Reactive Power Compensation Study. 2010. Available online: https://www.hitachienergy.com/ru/ ru/case-studies/reference-crez (accessed on 3 August 2020).

47. Huang, S.H.; Schmall, J.; Conto, J.; Adams, J.; Zhang, Y.; Carter, C. Voltage Stability Concerns on Weak Grids with High Penetration of Wind Generation: ERCOT Experience. In Proceedings of the IEEE PES General Meeting, San Diego, CA, USA, 22-26 July 2012.

48. Kong, D. Advanced HVDC systems for renewable energy integration and power transmission: Modelling and control for power system transient stability. Ph.D. Thesis, University of Birmingham, Birmingham, UK, June 2013.

49. Prabha, K.; John, P.; Venkat, A.; Göran, A.; Anjan, B.; Claudio, C.; Nikos, H.; David, H.; Alex, S.; Carson, T.; et al. Definiation and classification of power system stability. IEEE Trans. Power Syst. 2004, 19, 1387-1401.

50. The Republic of Iraq, Ministry of Electricity, Planning and Studies Office. Yearly Report; Ministry of Electricity, Planning and Studies Office: Baghdad, Iraq, 2017.

51. Israa, I.H.; Sirine, E.; Adel, K. Comparative study of HVDC and HVAC systems in presence of large scale renewable energy sources. In Proceedings of the 20th International Conference IEEE on Sciences and Techniques of Automatic Control and Computer Engineering (STA IEEE Conference), Monastir, Tunisia, 20-22 December 2020. 